\title{
Microfabrication and characterization of an array of dielectric elastomer actuators generating uniaxial strain to stretch individual cells
}

\author{
S Akbari and H R Shea \\ Microsystems for Space Technologies Laboratory, École Polytechnique Fédérale de Lausanne (EPFL), \\ Rue Jaquet Droz 1, Case Postal 526, 2002 Neuchâtel, Switzerland \\ E-mail: samin.akbari@epfl.ch
}

Received 29 August 2011, in final form 6 February 2012

Published 19 March 2012

Online at stacks.iop.org/JMM/22/045020

\begin{abstract}
Cells regulate their behavior in response to mechanical strains. Cell cultures to study mechanotransuction are typically $\mathrm{cm}^{2}$ in area, far too large to monitor single cell response. We have developed an array of dielectric elastomer microactuators as a tool to study mechanotransduction of individual cells. The array consists of $72100 \mu \mathrm{m} \times 200 \mu \mathrm{m}$ electroactive polymer actuators which expand uniaxially when a voltage is applied. Single cells will be attached on each actuator to study their response to periodic mechanical strains. The device is fabricated by patterning compliant microelectrodes on both sides of a $30 \mu \mathrm{m}$ thick polydimethylsiloxane membrane, which is bonded to a Pyrex chip with $200 \mu \mathrm{m}$ wide trenches. Low-energy metal ion implantation is used to make stretchable electrodes and we demonstrate here the successful miniaturization of such ion-implanted electrodes. The top electrode covers the full membrane area, while the bottom electrodes are $100 \mu \mathrm{m}$ wide parallel lines, perpendicular to the trenches. Applying a voltage between the top and bottom electrodes leads to uniaxial expansion of the membrane at the intersection of the bottom electrodes and the trenches. To characterize the in-plane strain, an array of $4 \mu \mathrm{m}$ diameter aluminum dots is deposited on each actuator. The position of each dot is tracked, allowing displacement and strain profiles to be measured as a function of voltage. The uniaxial strain reaches $4.7 \%$ at $2.9 \mathrm{kV}$ with a $0.2 \mathrm{~s}$ response time, sufficient to stimulate most cells with relevant biological strains and frequencies.
\end{abstract}

(Some figures may appear in colour only in the online journal)

\section{Introduction}

Polymer-based actuators are inherently lightweight and compliant, and offer an appealing alternative to more conventional actuators (e.g., electromagnetic motors and capacitive MEMS) especially for systems that must be flexible or stretchable. Because electroactive polymers (EAPs) have properties similar to a natural muscle, they are commonly referred to as artificial muscles. One type of electrostatically actuated EAP, the dielectric elastomer actuator (DEA), combines large displacements and high energy density (3.4 MJ.m ${ }^{-3}$ for $3 \mathrm{M}$ VHB acrylic elastomers) with low energy consumption, only dissipating power when moving [1, 2]. High voltages are required, generally several kilovolts. Since the electrostatic force scales as the inverse of the dielectric thickness, DEAs are excellent candidates for miniaturization. Most DEA devices to date have been at least cm-scale (e.g., arm-wrestling robots [3], or compact motors [4]; see [5] for a review) to meter-scale (e.g., for energy harvesting from waves [6] or for airships [7]). Yet, there is an increasing research activity on mm-scale devices, for instance for tactile displays $[8,9]$ and interest in going to even smaller scales. 
Miniaturization of DEAs is challenging principally due to the difficulties in fabricating $\mu \mathrm{m}$-scale electrodes that must: (1) be compliant to not limit the elastomer's deformation, and (2) remain conductive at strains from 3\% to $200 \%$. Despite the five orders of magnitude larger Young's modulus of metals than most silicones, evaporating thin metal films is one possibility: Pimpin et al patterned $180 \mu \mathrm{m}$ thick $45 \mu \mathrm{m}$ wide evaporated gold electrodes on an elastomer to make buckling mode microactuators. The evaporated gold electrodes, though patterned to minimize their stiffening effect, have an important impact on the rigidity of the polymer membrane [10]. Aschwanden and Stemmer have patterned $100 \mu \mathrm{m}$ wide carbon powder electrodes on a pre-stretched VHB membrane using a polydimethylsiloxane (PDMS) stamp to make tunable gratings [11]. Carbon powder has negligible impact on the stiffness, but it is not cleanroom compatible. Lotz et al have sprayed graphite powder over a shadow mask in order to fabricate mm-size stacked actuators used in peristaltic pumps or tactile displays [9]. In earlier work, our group has demonstrated the effective scaling of DEAs to the mm-scale using electrodes made by low-energy $(5 \mathrm{keV})$ gold ion implantation into PDMS [12, 13]. The electrodes are patternable in $\mu \mathrm{m}$-scale and present a low surface resistance $(<1 \mathrm{k} \Omega$ per square); they can be stretched up to $175 \%$ strain and survive more than 100000 cyclic deformations to $30 \%$ strain. Crucially, the ion-implanted electrodes have a low impact on Young's modulus of the elastomer on which they are patterned (40\% relative increase) thanks to the formation of a gold-PDMS nanocomposite [14, 15].

In this work, we have further miniaturized the ionimplanted electrodes to make an array of $100 \mu \mathrm{m} \times$ $200 \mu \mathrm{m}$ microactuators to stretch single cells that will be attached on top of each actuator. Cells modulate their behavior in response to mechanical stresses. Extracellular forces are transduced across the cell membrane and affect intracellular biochemical events such as proliferation, differentiation, alignment, apoptosis and signaling [16-18]; see [19] for a review. A variety of stretchable cell culture substrate systems have been developed, as reviewed by Brown [20]. These cell cultures are mostly $\mathrm{cm}^{2}$ large and therefore give the averaged response of 100000 s of cells at the same strain level. A few microelectromechanical systems on silicon substrate have been developed to apply uniaxial or biaxial strain to single cells $[21,22]$. These devices have a very low throughput, meaning that they can stretch only a single cell at one run.

We have developed an array of dielectric elastomer microactuators as a high throughput single cell stretcher device. The device is composed of 72 microactuators that can be actuated in three independent groups, thus applying different strain levels on multiple single cells in the same cell culture in one experiment. The microactuators are on a $30 \mu \mathrm{m}$ thick PDMS membrane proven to be biocompatible [23] and can be stretched uniaxially up to $4.7 \%$, tunable with the applied voltage. Focus of the current contribution is on the design, fabrication and characterization of the EAP microactuators.

\section{Microactuators' design and modeling}

In this section, the operating principle of one cell stretcher is described, and finite element simulations are used to predict actuator's performance. Our objective is an array of actuators to which single biological cells can be attached and stretched with relevant biological periodic strains. The desired strain level varies depending on the cell type. Bone cells respond to even below $1 \%$ mechanical strain [16] and to stimulate muscle cells, $2 \%-15 \%$ strain is required [17]. To allow for high throughput, array of cell stretcher actuators is fabricated and grouped into sub-arrays so that the effect of varying strain level or actuation frequency can be studied in a single cell culture.

\subsection{Actuation principle}

A DEA consists of a thin soft elastomer confined between two compliant electrodes. When a voltage is applied to the electrodes, the electrostatic pressure squeezes the elastomer between the electrodes. Since the elastomer is incompressible, it must expand in the in-plane directions. In the case of free boundary conditions, for strains of less than $10 \%$ on a non-prestretched elastomer, and assuming a linear correlation between stress and strain, the strain in the thickness direction is given by

$$
S_{z}=-\frac{\varepsilon_{0} \varepsilon_{r}}{Y} \frac{V^{2}}{t^{2}},
$$

where $\varepsilon_{0}$ is the permittivity of vacuum, $\varepsilon_{r}$ is the relative permittivity of the elastomer, $Y$ is Young's modulus of the elastomer, $t$ is its initial thickness and $V$ is the applied voltage between the electrodes. The relative permittivity is considered as a constant neglecting the electrostrictive effect of the polymer as shown by Kofod et al [24].

Our microactuator consists of a $30 \mu \mathrm{m}$ thick PDMS membrane with a $100 \mu \mathrm{m}$ wide compliant microelectrode on one side and a blanket compliant electrode on the other side as schematically shown in figure 1 . In order to have uniaxial in-plane strain when a potential difference is applied between the blanket electrode and the microelectrode, the $y$-axis displacement is limited by bonding the membrane to a Pyrex chip with a $200 \mu \mathrm{m}$ wide and $100 \mu \mathrm{m}$ deep trench, which is perpendicular to the microelectrode. The actuator is thus at the intersection of the microelectrode and the $200 \mu \mathrm{m}$ channel over which the electrostatically compressed membrane is free to expand in-plane.

Once the actuator is fabricated, a single cell will be attached on the actuator and stretched uniaxially when the membrane expands over the trench. This is feasible by either patterning cell-adherent extracellular-matrix protein on the actuator or patterning protein repellent co-polymers such as poly-l-lysine grafted polyethylene glycol on the surface except on the actuators by microcontact printing [25, 26].

The cells will be immersed in a conductive cell culture medium, which will be grounded with the top electrode and the high voltage is applied to the bottom microelectrodes. This configuration ensures that the electric field reaching the surface by a fringe field through the air is eliminated and 
Off state:

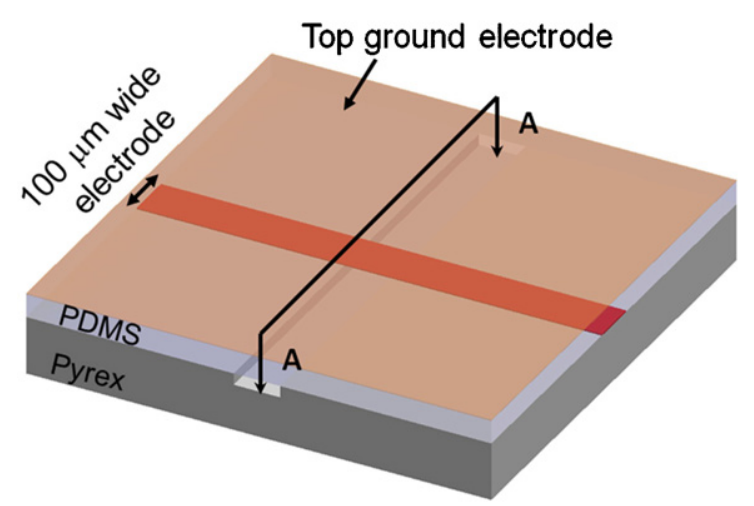

(a)

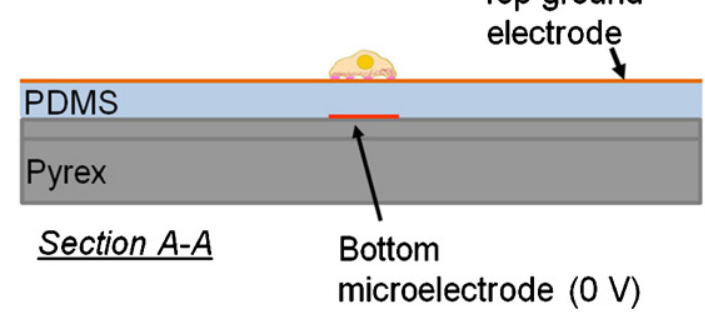

(b)
Actuated state:

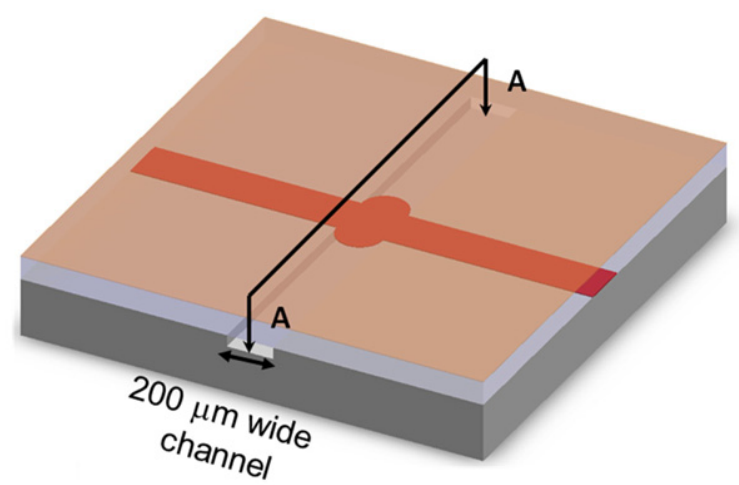

(c)

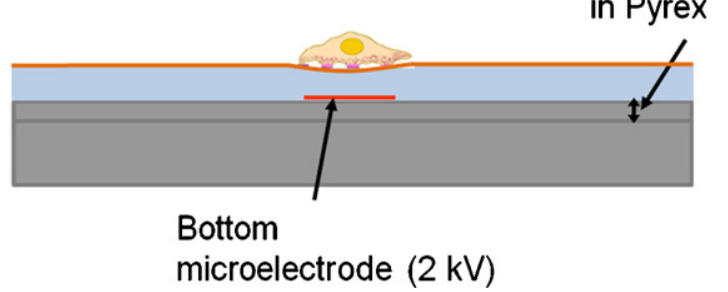

(d)

Figure 1. (a) Schematic of one cell stretcher, consisting of a $30 \mu \mathrm{m}$ thick PDMS membrane bonded on a Pyrex chip with a $200 \mu \mathrm{m}$ wide trench. The red line represents the $100 \mu \mathrm{m}$ wide ion-implanted gold electrode on the bonded side (bottom) of the membrane and there is a blanket ion-implanted electrode on top (brown rectangle). (b) Cross-sectional view (section A-A) of the device showing a single cell adhered on top of the actuator at the off state. (c) Actuated state of the device, explaining that when a high voltage is applied to the bottom microelectrode, the membrane compresses in thickness and expands uniaxially over the trench. Thus, the actuator is at the intersection of the microelectrode and the trench. $(d)$ Cross-sectional view of the actuated state of the cell stretcher, showing that a single cell attached on the actuator is stretched with the substrate.

the cells' behavior is only affected by the mechanical field as the cells are sensitive to the electric fields of higher than $1 \mathrm{~V} \mathrm{~cm}^{-1}$ [27].

\subsection{Design considerations}

DEAs are particularly well suited to cell stretching devices as they can be made on soft biocompatible silicone membranes on which cells are cultured. Besides, the cells are much softer (Young's modulus $0.2-40 \mathrm{kPa}$ [28]) than the polymer membranes used in EAPs (Young's modulus of order $1 \mathrm{MPa}$ ), thus imposing a negligible effect on the actuation strain of the actuators. The drawback of DEAs is the required high-voltage equipments as the actuation voltage is in the order of $\mathrm{kVs}$. By isolating the high-voltage electrodes and shielding the electric field through the air, it can be ensured that the cells will not behave under the influence of the electric field.

To decrease the required voltage to reach the desired strain levels, using a polymer with high dielectric constant and low Young's modulus is helpful (refer to equation (1)). We use Sylgard 186 (from Dow Corning), which is softer than Sylgard 184, traditionally used to mold channels for microfluidic applications. This silicone film has the dielectric constant of 2.7 at $100 \mathrm{~Hz}$, lower than the dielectric constant of acrylic adhesives from $3 \mathrm{M}$ (4.65 for $\mathrm{VHB}^{\mathrm{TM}} 4910$ ). But it is still preferred in our case due to its negligible viscoelastic behavior ensuring repetitive actuation strain and stable dynamic behavior [29].

Thickness is the other key parameter in decreasing the actuation voltage. The electric field is higher in thinner membranes at a certain voltage, resulting in a higher electrostatic pressure and thus higher strains. The membranes with the thickness of $25-30 \mu \mathrm{m}$ are used in our actuators to not require actuation voltages of more than $4 \mathrm{kV}$ and to not be so fragile.

Size of the actuator defined by width of the microelectrode and width of the trench has a minor effect on its actuation strain as previously reported by the authors [30]. The actuator's size is designed close to the size of the single cells, which vary from 10 to $50 \mu \mathrm{m}$ depending on the cell type. One limiting factor in downsizing the microactuator is the aspect ratio of the shadow mask used to pattern the ion-implanted electrode as it affects the concentration of the gold dose for the aspect ratios of less than 1 . Since we are using $70 \mu \mathrm{m}$ thick shadow masks, we have chosen $100 \mu \mathrm{m}$ wide ion-implanted electrodes. The geometrical optimization carried out by a finite element analysis has shown that the actuators with wider trenches have higher actuation strain at a certain voltage [30]. That is why, $200 \mu \mathrm{m}$ wide trenches are selected for the actuators.

It has been shown that pre-stretching the membrane modifies the performance of the DEAs by increasing the breakdown electric field and modifying stiffness of the 

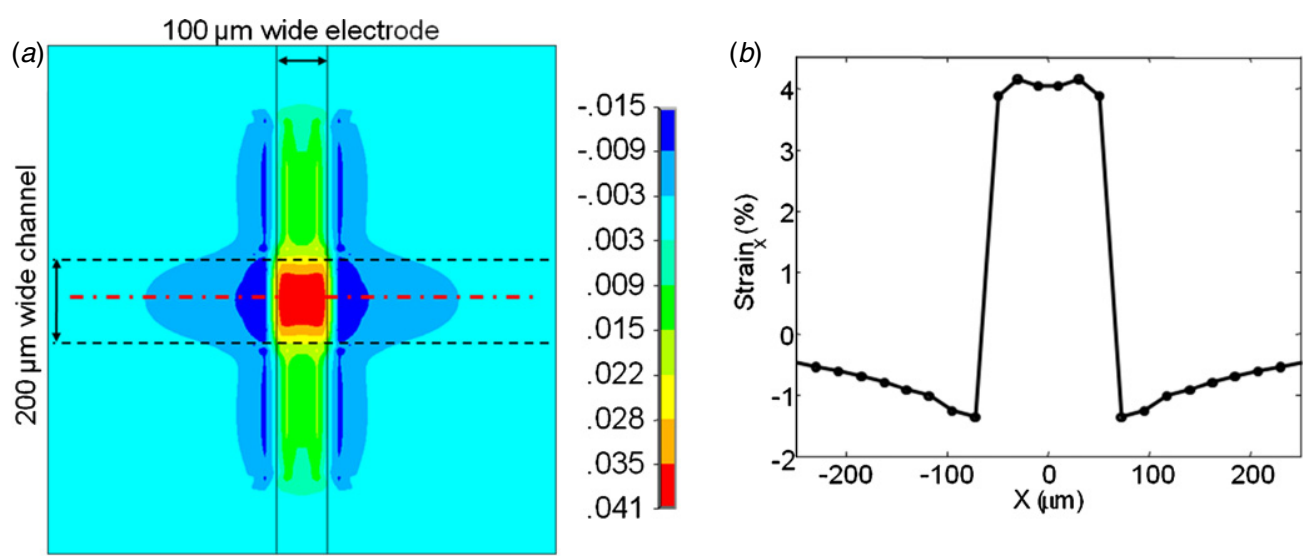

Figure 2. (a) Simulated $x$-axis strain profile of the actuator, when $2.6 \mathrm{kV}$ is applied between the electrodes. The strain is constant over the actuator, i.e. over the intersection of the $100 \mu \mathrm{m}$ wide electrode and the $200 \mu \mathrm{m}$ wide trench. (b) Computed $x$-axis strain plotted on the centerline of the actuator, showing that the strain is maximum and constant on the actuator. $4.1 \%$ strain is obtained using the material properties listed in table 1 .

Table 1. Geometrical dimensions and material properties used in the FEM simulation.

\begin{tabular}{llll}
\hline Geometrical dimensions & Material properties \\
\hline Width of high-voltage ion- implanted electrodes. & $100 \mu \mathrm{m}$ & Young's modulus of double side ion-implanted elastomer. & $2.5 \mathrm{MPa}$ \\
Width of channels in the rigid substrate. & $200 \mu \mathrm{m}$ & Young's modulus of one side ion-implanted elastomer. & $1.8 \mathrm{MPa}$ \\
Thickness of membrane. & $30 \mu \mathrm{m}$ & Relative permittivity of elastomer. & 2.7 \\
\hline
\end{tabular}

elastomer [31, 32]. In our design, the PDMS membrane is bonded to a Pyrex chip by oxygen plasma activation which has an average bond strength of $300 \mathrm{kPa}$ [33], corresponding to $20 \%$ pre-stretch of Sylgard 186 . To avoid debonding due to the pre-stretch, we use a non-stretched membrane for the actuators.

\subsection{Finite element analysis}

Numerical analysis of one single actuator is carried out in ANSYS [34] to study strain and deflection of the device versus voltage and geometry, and to predict the critical buckling voltage beyond which uniaxial strain is no longer possible. The geometrical optimization of the actuator has been previously reported by the authors using a simplified finite element method (FEM) model [30]. In this study, we have performed more accurate simulations on the optimized geometry using similar material properties as the fabricated device. The comparison of the numerical and experimental results is discussed in section 4.1.

A coupled field element Solid 226 is used to mesh $1 \mathrm{~mm} \times 1 \mathrm{~mm}$ elastomer with a $100 \mu \mathrm{m} \times 200 \mu \mathrm{m}$ actuator at the center. The geometrical dimensions and the material properties used in the simulation are listed in table 1, which are identical to the fabricated actuators in order to compare the numerical and experimental results. The dielectric constant is taken from the published datasheet of Sylgard 186 [35]. For the ion-implanted PDMS, we have not modeled the nmscale gold clusters inside the PDMS, as the relevant point is that patterning the compliant electrodes by implanting gold ions into the PDMS membrane increases Young's modulus of the gold-elastomer composite. We have considered different Young's moduli for the area that is implanted on one or both sides. We were not able to measure Young's modulus of our $100 \mu \mathrm{m}$ wide ion-implanted electrodes directly. Therefore, in the simulation we used Young's modulus of a $2 \mathrm{~mm}$ diameter $30 \mu \mathrm{m}$ thick PDMS membrane with one side and both sides ion-implanted electrodes at similar doses measured using a bulge test setup [14, 15]. A linear stress-strain relationship and a Poisson ratio of 0.49 are assumed which is a valid assumption for our case with less than $10 \%$ strain.

To model the actuator as described in figure 1, a voltage is applied between the $100 \mu \mathrm{m}$ wide electrode on the bottom surface of the $30 \mu \mathrm{m}$ thick elastomer and the top electrode. The nodes on the bottom layer of the membrane are fixed in all three directions except over the $200 \mu \mathrm{m}$ wide channel, as it well simulates bonding of the membrane to a Pyrex chip with etched channels. Along the $100 \mu \mathrm{m}$ wide electrodes, Young's modulus is higher, as in this area, both sides of the elastomer are ion implanted.

Following a coupled field analysis, the computed $x$-axis strain profile is plotted in figure 2(a), showing that the $x$-axis strain is maximum and constant over the actuator. The strain along the centerline of the actuator is plotted in figure $2(b)$, showing that $4.1 \%$ strain is predicted at $2.6 \mathrm{kV}$ using the material properties listed in table 1 . Having a constant strain on an area of $100 \mu \mathrm{m}^{2}$ on the actuator ensures that a cell will sense a uniform force.

The actuation strain of the DEA can be increased until it fails due to breakdown of the dielectric, instability mode, rupture of the membrane or loss of tension. In our case, as we want to stretch the cells with calibrated in-plane uniaxial strain, the buckling mode, where the strain field is biaxial and out of plane, is considered a failure. Since the membrane is not prestretched, the actuator buckles at the certain strain, at which the compressive force in the non-implanted membrane exceeds 


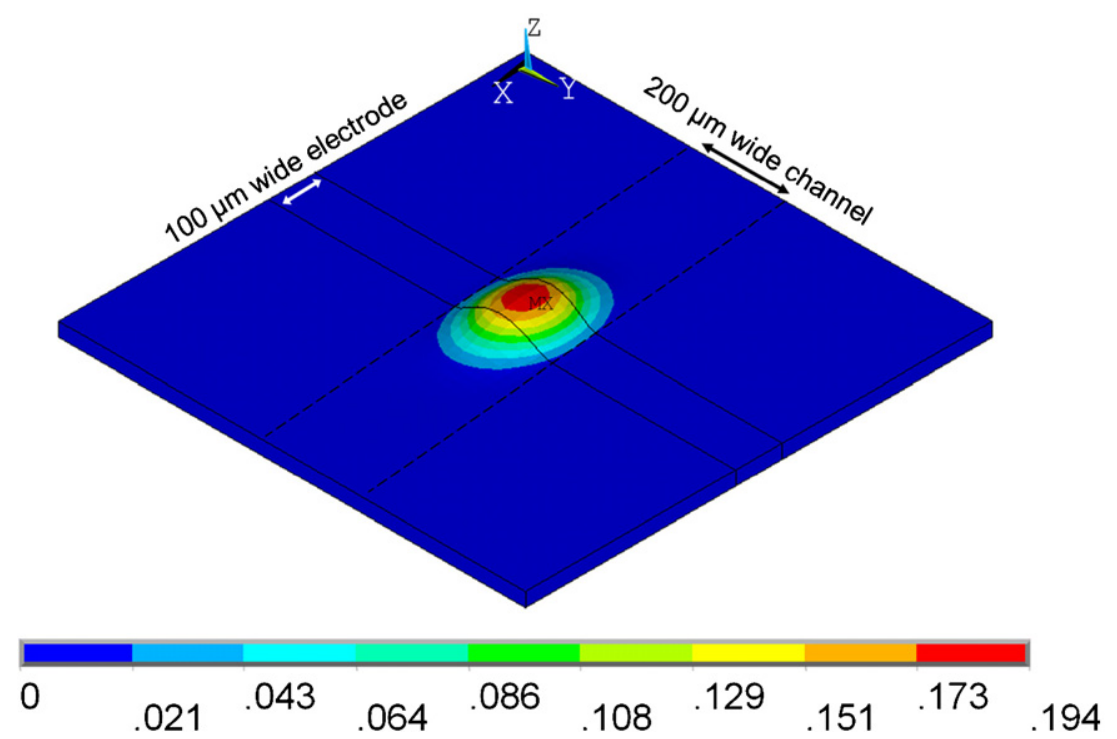

Figure 3. Simulated first buckling mode of a $100 \mu \mathrm{m} \times 200 \mu \mathrm{m}$ actuator on a $30 \mu \mathrm{m}$ thick PDMS membrane at $3.97 \mathrm{kV}$. The contour legend shows the relative displacement of the mode shape.

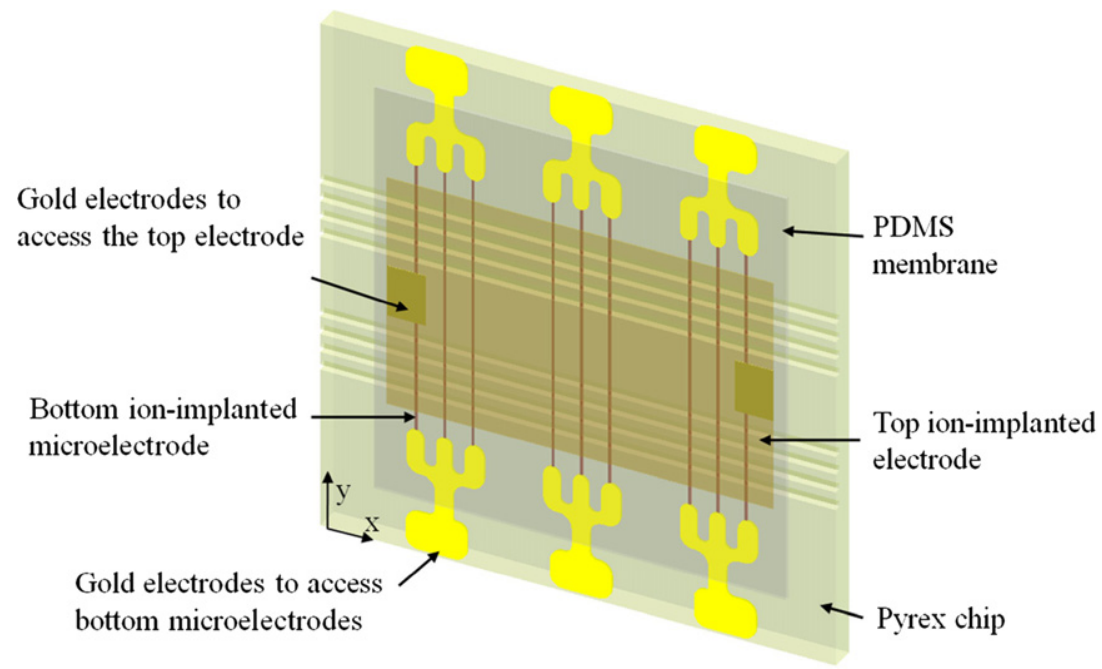

Figure 4. Array of 72 microactuators.

the buckling limit. A linear buckling analysis is performed in order to estimate the critical buckling voltage for our actuators. The first buckling mode is shown in figure 3, which occurs at $3.97 \mathrm{kV}$. The computed actuation uniaxial strain before buckling at $3.8 \mathrm{kV}$ is $12 \%$ which is a promising value that can cover the desired strain for stimulating most cell types.

\section{Microfabrication}

A schematic diagram of an array of 72 microactuators composed of a $30 \mu \mathrm{m}$ thick PDMS membrane with nine microelectrodes bonded on a Pyrex chip with eight trenches is shown in figure 4 . The device is electrically grouped into three groups of 24, to allow three different frequencies or amplitudes on a given chip. Electrical contact to the bottom ion-implanted lines is an important aspect, and the Pyrex chip serves both as a support for the EAP device and as a support for thicker gold pads to which wirebonded connections can be made. As the actuators operate independently, their quantity in the array can easily be increased by adding more microelectrodes on the membrane or more channels in the Pyrex chip, without influencing the actuation strain of individual actuators.

The fabrication process of the array of uniaxial cell stretchers is shown in figure 5. The main fabrication steps are summarized in this paragraph, and then discussed below. First, Pyrex chips with patterned gold electrodes and etched $200 \mu \mathrm{m}$ wide trenches are fabricated. Then, a $30 \mu \mathrm{m}$ thick PDMS membrane is prepared and $100 \mu \mathrm{m}$ wide compliant electrodes are patterned on it with low-energy ion implantation. Finally, the membrane is bonded to the Pyrex chip and a blanket electrode is ion-implanted on the top surface.

\subsection{Fabrication of Pyrex chips with patterned gold electrodes and etched channels}

In order to confine the in-plane expansion of the membrane along one axis, the membrane is bonded to a rigid substrate 


\section{Sylgard $186 \square$ Polyimide $\square$ Pyrex Teflon film}

Evaporated/ Sputtered Gold @ Ion-implanted gold

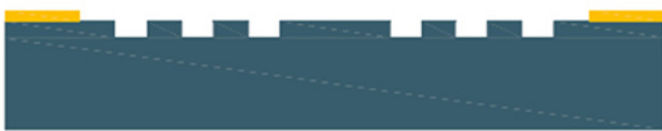

(a)

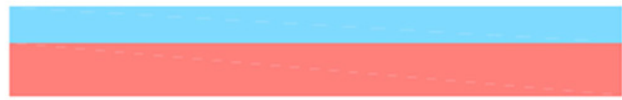

(b)

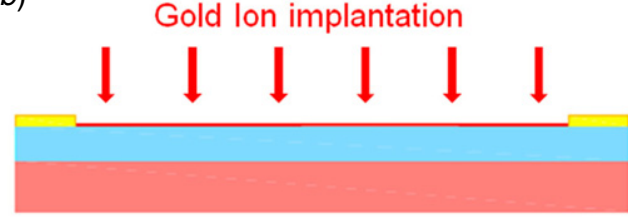

(c)

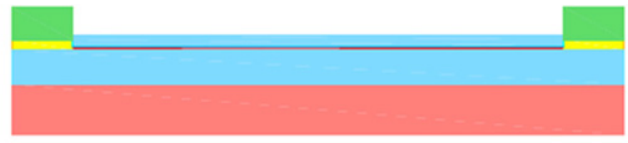

$(d)$

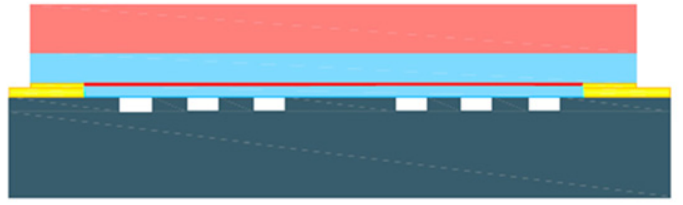

$(e)$

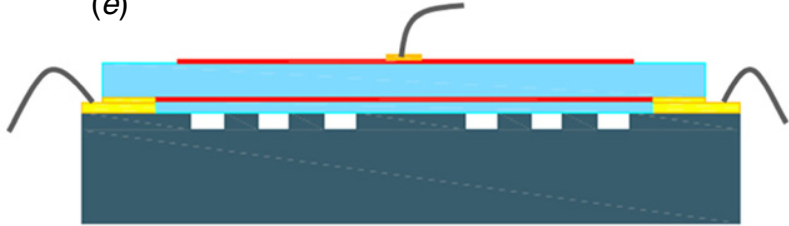

$(f)$

Figure 5. (a) Gold electrodes are patterned on a Pyrex substrate and $200 \mu \mathrm{m}$ wide $100 \mu \mathrm{m}$ deep trenches are etched by powder blasting. (b) $30 \mu \mathrm{m}$ thick PDMS membrane is casted over a support film (polyimide from Kapton). (c) The gold ions are selectively implanted through a shadow mask in our ion implanter at the energy of $-2.5 \mathrm{keV}$ and the gold contacts at the end of the implanted lines are deposited. (d) A thin layer of PDMS is casted over the main film and cured while the contact pads are protected. $(e)$ The PDMS membrane is chemically bonded to the substrate. $(f)$ The support film is removed and the top layer of the membrane is ion implanted and the top gold contacts are deposited by sputtering.

with channels inside. Previously, we have reported using a $2 \mathrm{~mm}$ thick PDMS (Sylgard 184) substrate with $100 \mu \mathrm{m}$ wide channels, which were patterned by molding the uncured PDMS over a SU-8 mold [30]. In this design, we have used $500 \mu \mathrm{m}$ thick Pyrex chips with $200 \mu \mathrm{m}$ wide trenches. Pyrex is much stiffer than PDMS and it is easier to make reliable electrical contacts on it.

The Pyrex chips are fabricated at the wafer level; first, gold electrodes are patterned on a $500 \mu \mathrm{m}$ thick Pyrex wafer using a liftoff process with a negative photoresist (AZ 5214). The thickness of the evaporated gold is $200 \mathrm{~nm}$ on a $20 \mathrm{~nm}$ thick chromium adhesion layer. This thickness is sufficient to connect to wires using wire bonding or low-temperature soldering. Then, $200 \mu \mathrm{m}$ wide and $100 \mu \mathrm{m}$ deep channels are etched in the wafer by powder blasting [36]. Powder blasting leads to sidewalls with an approximately $15^{\circ}$ angle, with a roughness of order $0.8 \mu \mathrm{m}$. Finally, the wafer is diced to $20 \mathrm{~mm} \times 20 \mathrm{~mm}$ chips.

The gold electrodes patterned at two edges of the Pyrex chip will serve to contact the microelectrodes patterned on the bottom (bonded) layer of the membrane. Pyrex chip is slightly larger than the membrane so that the gold electrodes on the Pyrex can be easily contacted after assembly.

\subsection{Fabrication of $30 \mu \mathrm{m}$ thick PDMS membrane}

Two components of Sylgard 186 from Dow Corning are mixed with 10:1 weight ratio as recommended by the manufacturer and diluted with iso-octane (PDMS:Solvent 10:9 weight) in order to decrease its viscosity. The mixture is degassed for 30 min until all the trapped air bubbles are released. A universal applicator ZUA 2000 from Zehntner GmbH Testing Instruments is used to cast the PDMS mixture on a $55 \mu \mathrm{m}$ thick polyimide film as a support. The parameters are adjusted to have $30 \mu \mathrm{m}$ thick membranes. The film is cured at $100{ }^{\circ} \mathrm{C}$ for $40 \mathrm{~min}$ in the oven. The PDMS membrane is then cut to $17 \mathrm{~mm} \times 17 \mathrm{~mm}$ pieces.

\subsection{Compliant electrodes by low-energy ion implantation}

In order to pattern compliant electrodes on the PDMS membrane, we implant the gold ions into the PDMS membrane at energies lower than $5 \mathrm{keV}$ using a filtered cathodic arc vacuum source. This leads to nm-sized gold clusters in the top $50 \mathrm{~nm}$ of the PDMS surface that creates a conductive path sustaining up to $175 \%$ uniaxial stretch before break $[14,15]$. Increasing the gold dose not only increases the conductivity, but also increases the stiffness of the goldPDMS composite. Just above the percolation threshold, the conductivity is good enough for the DEAs $(1 \mathrm{k} \Omega$ /square) and Young's modulus of the gold-implanted PDMS is increased about $40 \%$ compared to non-implanted PDMS. Our group has shown that ion implantation is an effective technique for making mm-scale EAPs, for instance buckling mode actuators [12], tunable lenses [37] or tunable acoustic filters [38].

The smallest electrode patterned by ion implantation in aforementioned actuators was of $1.5 \mathrm{~mm}$ diameter and here, we have further miniaturized the implanted features to pattern $100 \mu \mathrm{m}$ wide electrodes. The linear correlation existing between the ion dose and the number of implantation arc pulses for the mm-scale electrodes is no more valid for the microelectrodes and a new calibration curve is required. Due 


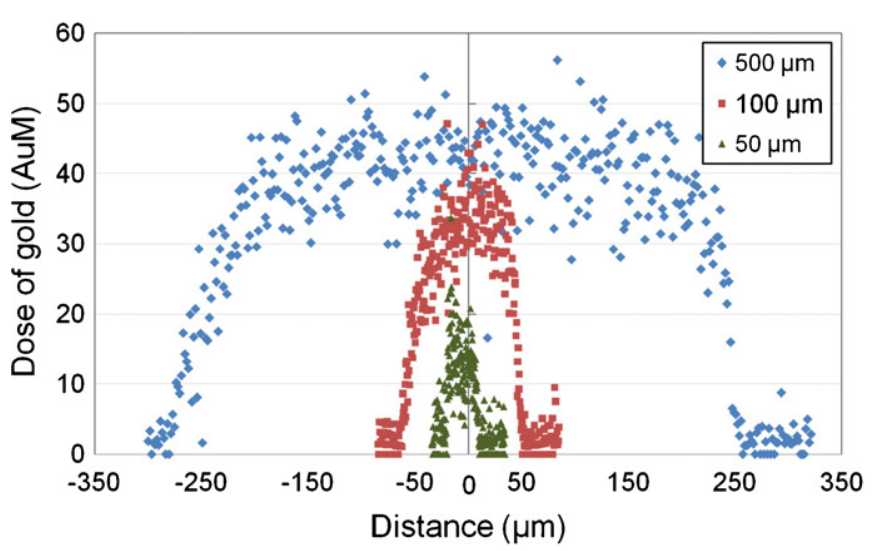

Figure 6. EDS mapping of amount of gold atoms in the ion-implanted electrodes versus position from the center of the line. The ion implantation is performed through $100 \mu \mathrm{m}$ thick shadow mask of widths 500, 100 and $50 \mu \mathrm{m}$. The aspect ratio of the mask affects the maximum concentration: if the aspect ratio of the shadow mask is less than 1, a significant portion of the ion beam no longer reaches the PDMS.

to geometrical effect of the shadow mask and charge trapping during the implantation, the aspect ratio of the mask affects the ion dose implanted in the elastomer. During the implantation, the mask is negatively charged as it is connected to the negative bias voltage and therefore, the mask's walls attract the positive gold ions reducing the dose of the gold ions passing through. The gold atoms in 500, 100 and $50 \mu \mathrm{m}$ wide ionimplanted electrodes are detected with an energy dispersive $\mathrm{x}$ ray spectroscopy (EDS) in an environmental scanning electron microscope and mapped in figure 6 . The ion implantation was performed with the energy of $-5 \mathrm{keV}$ through a $100 \mu \mathrm{m}$ thick conductive mask. It is observed that the concentration of gold is significantly decreased for aspect ratios below 1 .

To decrease the mask's effect on the ion dose, $70 \mu \mathrm{m}$ thick shadow masks are used to pattern $100 \mu \mathrm{m}$ wide electrodes on a $17 \mathrm{~mm} \times 17 \mathrm{~mm}$ PDMS film. The implantation energy is decreased to $-2.5 \mathrm{keV}$ as it reduces the attraction of the positive gold ions to the negative mask walls. With these modifications, half of the previous implantation pulses are sufficient to pattern electrodes at a dose slightly higher than the percolation threshold. In this case, the resistivity of the electrodes is at the order of $1 \mathrm{k} \Omega$ /square and Young's modulus of PDMS is increased about $40 \%$. Afterward, gold electrodes with the same shape as the ones on the Pyrex chip are patterned at the ends of the ion-implanted electrodes using a sputter coater through a shadow mask. After bonding the membrane to the Pyrex chip, the patterned gold electrodes on the chip create a conducting path to access the bottom-implanted electrodes.

\subsection{Bonding}

A high bond strength between the PDMS membrane and the Pyrex chip is required at the edges of the actuators to ensure reliable operation. We need to bond both the pristine PDMS and the ion-implanted electrodes to the Pyrex chip. Traditional plasma $\mathrm{O}_{2}$ bonding methods do not activate the surface of gold ion-implanted PDMS and hence, it is not effective for pyrex to ion-implanted PDMS bonding. Other techniques have been reported to bond two PDMS microfluidic chips, such as using uncured PDMS or curing agent of Sylgard 184/186 as an adhesive [39-41]. Employing these techniques, the bond strength is not satisfactory between our $30 \mu \mathrm{m}$ thick PDMS membrane and the Pyrex chip. Our solution is to cast a thin layer of uncured PDMS over the ion-implanted film and let it cure. This thin PDMS layer is well bonded to the ion-implanted PDMS, and the non-implanted PDMS layer on top bonds to the Pyrex chip by Plasma $\mathrm{O}_{2}$ activation (see figure $5(d)$ ). As this 'passive' layer reduces the strain, it is important to minimize its thickness and stiffness and hence, the two components of Sylgard 186 are mixed with 20:1 weight ratio as this makes a much softer film [42] and the PDMS is diluted with two times more solvent (PDMS: Solvent 1:2 weight) as it results to a thinner film. While casting the uncured PDMS with the applicator, the contact pads are protected with a $25 \mu \mathrm{m}$ thick teflon film (PFA from Dupont). The thin layer is cured at $65{ }^{\circ} \mathrm{C}$ for $4 \mathrm{~h}$. It is important to keep the curing temperature lower than $80{ }^{\circ} \mathrm{C}$ to not lose the conductivity of the ionimplanted electrodes on the PDMS due to different thermal expansion coefficients between gold and PDMS. The resulting 'passive' PDMS layer is $2.5 \mu \mathrm{m}$ and it is well bonded to the main ion-implanted PDMS membrane.

The pristine top of the 'passive' film is then bonded to the Pyrex chip by exposing both of them to oxygen plasma (15 s at $400 \mathrm{~W}$ and $2.45 \mathrm{GHz}$, with an $\mathrm{O}_{2}$ flow of $400 \mathrm{sccm}$ and at a pressure of $\sim 500$ mTorr). Before bonding, the Pyrex chips are washed with iso-propanol and then with deionized water and dried completely with nitrogen gas. Without using the intermediate layer and by directly bonding the ion-implanted PDMS membrane to the Pyrex chip by plasma $\mathrm{O}_{2}$, the $100 \mu \mathrm{m}$ wide electrodes do not bond to the Pyrex chip. This results in unstable actuation strain and lower buckling voltages, reducing the maximum achievable in-plain strain by $50 \%$.

At the final step of fabrication, the polyimide support film is removed and the compliant electrodes on top are patterned by ion implantation and two small gold contact pads are deposited by a sputter coater. To characterize the device, without the cell culture medium, a blanket electrode is implanted on top; otherwise, the conductive liquid will be used as the ground electrode, avoiding the slight stiffening effect of the top electrode.

Figure $7(a)$ shows a fabricated device consisting of $72100 \mu \mathrm{m} \times 200 \mu \mathrm{m}$ actuator in three independently controlled groups. Each group of 24 actuators is contacted by one trident-shaped electrode. The second trident-shaped electrode is used to measure the resistance of the $100 \mu \mathrm{m}$ wide ion-implanted wires to characterize the implantation dose. Each of the three groups can be actuated with different voltages and frequencies making it possible to stimulate different groups of cells with various strains in the same cell culture. The chip holder shown in figure $7(b)$ is designed to allow electrical contacts and safe operation when the top of the chip is immersed in conductive cell culture medium.

\section{Characterization}

The static and dynamic uniaxial strain profiles of the actuators are measured optically as a function of the drive voltage. The 
(a)

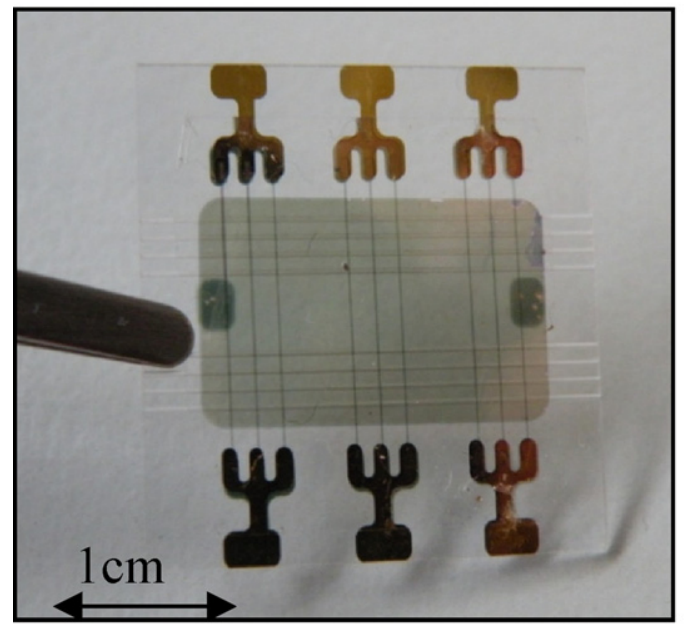

(b)

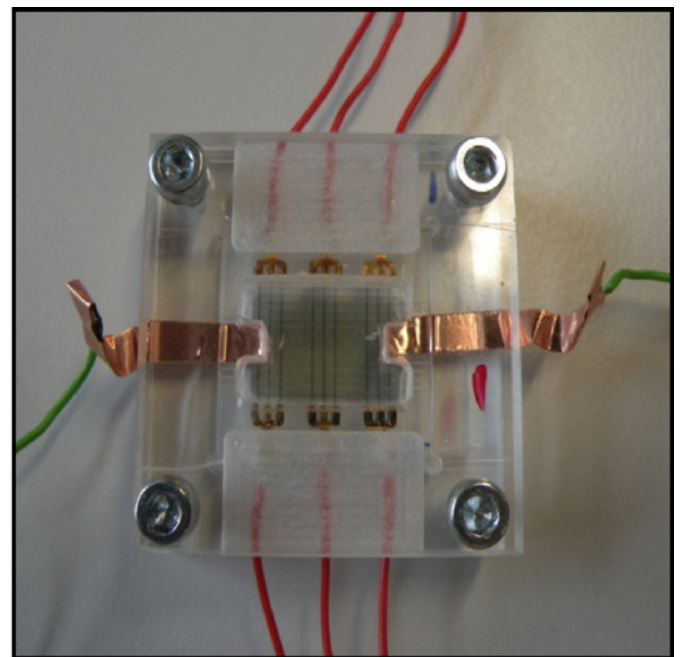

Figure 7. (a) Fabricated array of $72100 \mu \mathrm{m} \times 200 \mu \mathrm{m}$ dielectric actuators. (b) Device in its holder designed for ease of liquid handling. The green wires are connected to the ground electrode on top and the red ones are connected to the high voltage to the bottom electrodes.

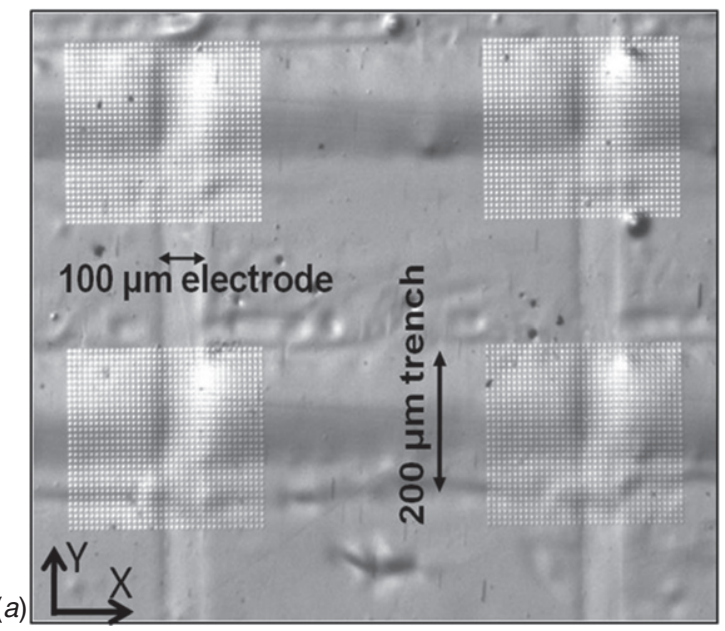

(b)

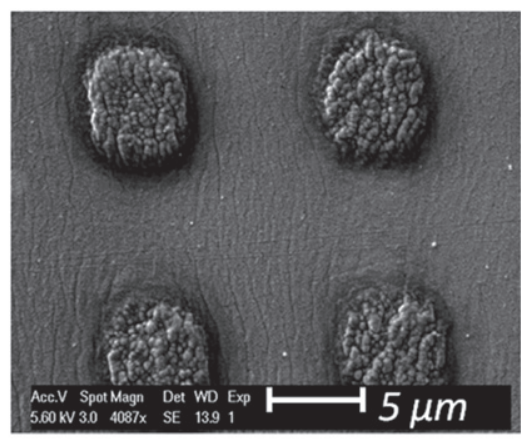

Figure 8. (a) Optical micrograph of four $100 \mu \mathrm{m} \times 200 \mu \mathrm{m}$ actuators. Arrays of $4 \mu \mathrm{m}$ diameter aluminum dots are deposited on the actuators through a stencil mask. (b) SEM micrograph of four $100 \mathrm{~nm}$ thick deposited aluminum dots.

uniformity of the actuators in the array is verified by comparing the actuation strain of 15 out of 24 actuators in one group of a device. The dynamic behavior of the actuators is studied, actuating them with square signals at frequencies of 0.5 and $1 \mathrm{~Hz}$, showing that the response time of the actuator is sufficient for stimulating the cells with relevant biological frequencies. The measured data match well with the FEM predictions.

\subsection{Static response}

The conventional method to measure the deflection of DEAs is to track the edges of the electrodes before and after applying the voltage. In our actuators, detecting the edges of the ionimplanted electrodes, which are at the bottom layer of the membrane covered with a blanket ion-implanted electrode on top of the membrane does not lead to accurate measurements especially for strain levels lower than $10 \%$. To accurately characterize the in-plane strain of the actuated devices, an array of $100 \mathrm{~nm}$ thick $4 \mu \mathrm{m}$ diameter aluminum dots is deposited through a stencil mask on each actuator (figure 8). The holes in the stencil are etched in a $500 \mathrm{~nm}$ thick silicon nitride membrane that enables depositing micrometer features using a thermal evaporator [43, 44]. The stencil mask is carefully aligned with the device to have an array of dots on each actuator, as seen in figure $8(a)$. The dots are spaced $14 \mu \mathrm{m}$ apart and cover an area of $500 \mu \mathrm{m} \times 400 \mu \mathrm{m}$ to monitor the deflection of the membrane on and around the $100 \mu \mathrm{m} \times$ $200 \mu \mathrm{m}$ actuators. It is important that the aluminum dots do not stiffen the membrane and reduce the actuation. To gauge this, we have performed a static finite element analysis in ANSYS to compute the effect of dots on Young's modulus of the PDMS membrane: the effective Young's modulus is increased by $1 \%$ when the dots are spaced $14 \mu \mathrm{m}$ and by $6.7 \%$ when the dots are spaced $9 \mu \mathrm{m}$ apart.

The dots are only deposited to characterize the strain of the device and will not be deposited on the devices made for cell stretching experiments.

The positions of all the dots are detected before and after applying the voltage with an image-processing program and subtracted from each other to calculate the displacement 

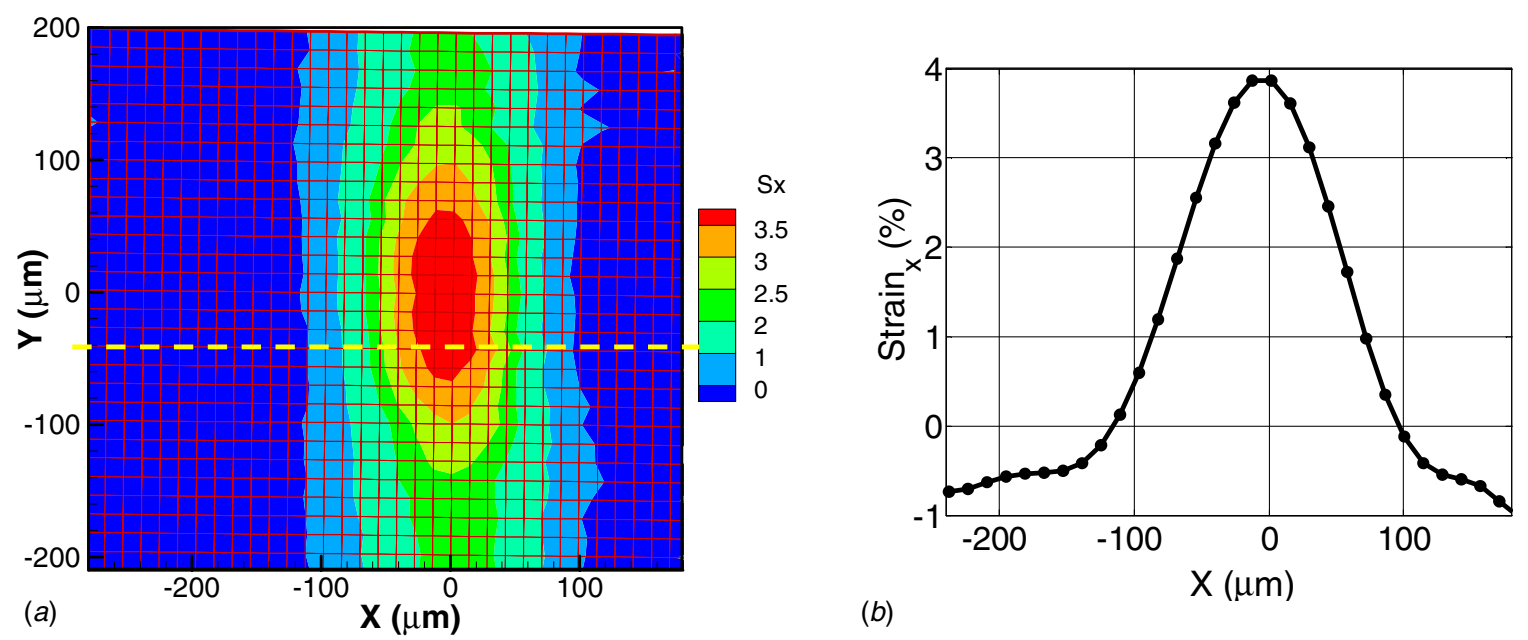

Figure 9. (a) Measured $x$-axis strain at $2.6 \mathrm{kV}$. Each node in the mesh represents one aluminum dot; center of the actuator is at $(0,0)$. The actuator is $100 \mu \mathrm{m} \times 200 \mu \mathrm{m}$ in a device with $30 \mu \mathrm{m}$ thick Sylgard 186 membrane. The intermediate PDMS layer used for bonding is $3 \mu \mathrm{m}$ thick (Sylgard 186, mixing ratio 1:20, (PDMS: Solvent, 1:2)). (b) Measured $x$-axis strain along the channel on the centerline of the actuator at $2.6 \mathrm{kV}$. The in-plane uniaxial strain at a $50 \mu \mathrm{m}^{2}$ area on the center of the actuator is $3.7 \%-3.9 \%$.

profile of the membrane. The $x$-axis strain is then calculated by differentiating the smoothed $x$-axis displacement along the $x$-axis.

The strain field is plotted in the color map in figure $9(a)$ for one actuator at $2.6 \mathrm{kV}$. Each node of the mesh represents one aluminum dot and the $x$-axis strain of the dot is mapped on the mesh. The results confirm that the in-plane strain exists along the electrode and reaches to the maximum over the channel on the actuator. The strain variation at the center of the actuator is negligible $(0.2 \%)$ for an area of $50 \mu \mathrm{m}^{2}$. It means that a single cell attached on the center of the actuator will sense a constant strain. The $x$-axis in-plane strain along the channel on the centerline of the actuator is plotted in figure $9(b)$.

The maximum measured strain is only $0.1 \%$ less than the maximum simulated $x$-axis strain presented in figure 2 on the center of actuator, despite the uncertainty in the exact Young's modulus of the ion-implanted electrodes. The simulated strain profile shows a constant strain at $100 \times 100 \mu \mathrm{m}^{2}$ area on the actuator, while this area is smaller in measurement. This discrepancy can be due to the details such as the electric field spread through the air in the channel or different Young's modulus of the $3 \mu \mathrm{m}$ thick intermediate layer that are neglected in simulation.

The actuation strain increases quadratically with the applied voltage as expected since the electrostatic pressure is proportional to the square electric field (figure 10). We achieved $4.7 \%$ strain at a voltage of $2.9 \mathrm{kV}$ before the membrane buckles and the actuation mode switches to biaxial out of plane strain from uniaxial in-plane strain. The strain level of our device is sufficient to mechanically stimulate most of the cell types.

The critical buckling voltage varies from 3 to $4.5 \mathrm{kV}$ for different fabricated devices depending on their initial thickness and thickness of their passive layer. Besides, the internal prestress caused during cross-linking of the main film or the passive layer influences the critical buckling voltage, which is not considered in the FEM simulations. Due to this fact, value of the computed critical buckling voltage is not the same as

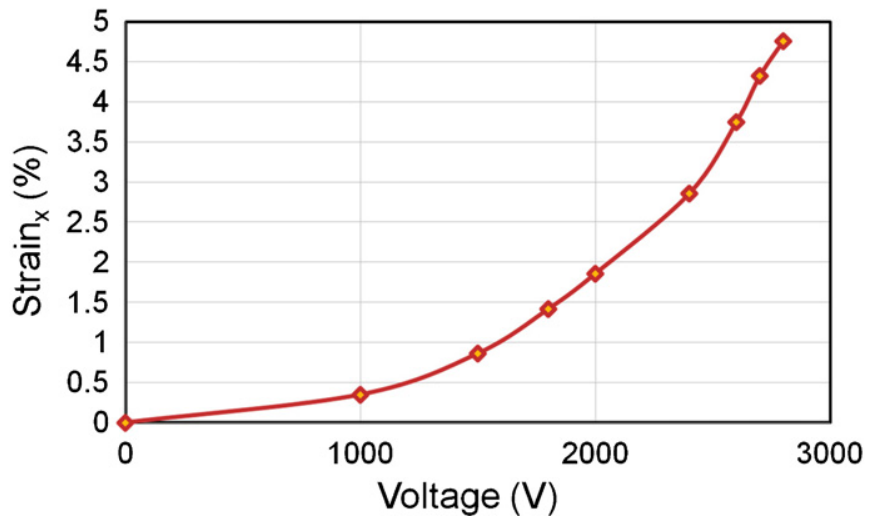

Figure 10. Measured $x$-axis in-plane strain versus drive voltage, showing the expected $V^{2}$ scaling. A maximum strain of $4.7 \%$ is observed at $2.9 \mathrm{kV}$.

the experimental buckling voltage and the membrane buckles at lower voltages. However, the experimentally observed buckling mode is the same as the computed mode shape (figure 3). The ultimate failure of our DEAs based on nonpre-stretched membranes with strain of lower than $10 \%$ is due to the electrical break down of the PDMS membrane.

To verify the uniformity of the actuation strain of the actuators on the array, we randomly tested 15 actuators in one of the three groups of the device at $2 \mathrm{kV}$. A histogram of the measured strain is plotted in figure 11 , showing that 10 out of 15 actuators have the strain between $1.9 \%$ and $2.15 \%$ and the strain of the other five actuators is $0.2 \%$ lower. Considering $0.1 \%-0.2 \%$ error in strain calculation of our image-processing technique, we believe that this strain disparity is very promising for an array of dielectric elastomer microactuators having polymers as their main components that can have non-uniform stiffness/thickness due to nonuniform cross-linking. Other sources of strain difference between multiple actuators in the array can be the stiffness inconsistency of the ion-implanted electrodes or thickness 


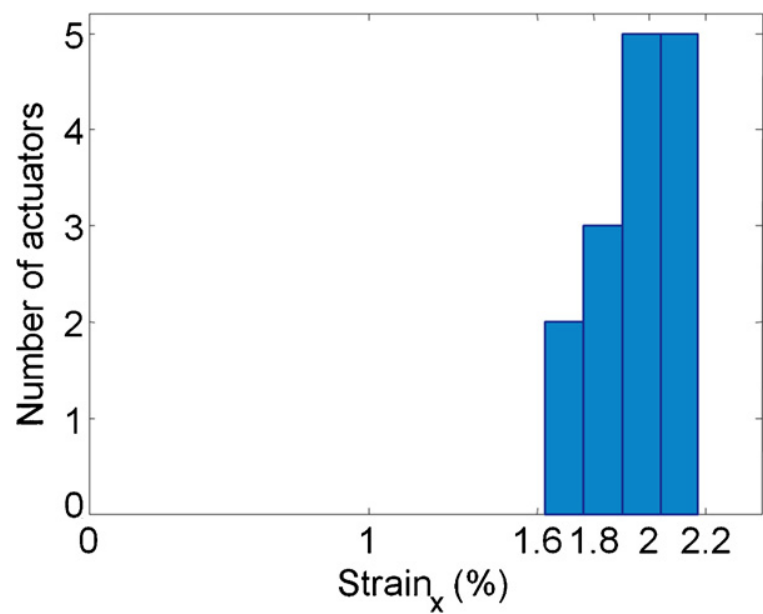

Figure 11. Histogram of the $x$-axis strain of 15 out of 24 actuators of one group of the device at $2 \mathrm{kV}$, showing consistent actuation strain over the multiple actuators. The actuator is $100 \mu \mathrm{m} \times$ $200 \mu \mathrm{m}$ on a $25 \mu \mathrm{m}$ thick Sylgard 186 membrane. The intermediate PDMS layer used for bonding is $2.5 \mu \mathrm{m}$ thick (Sylgard 186, mixing ratio $1: 20,200 \%$ iso-octane solvent).

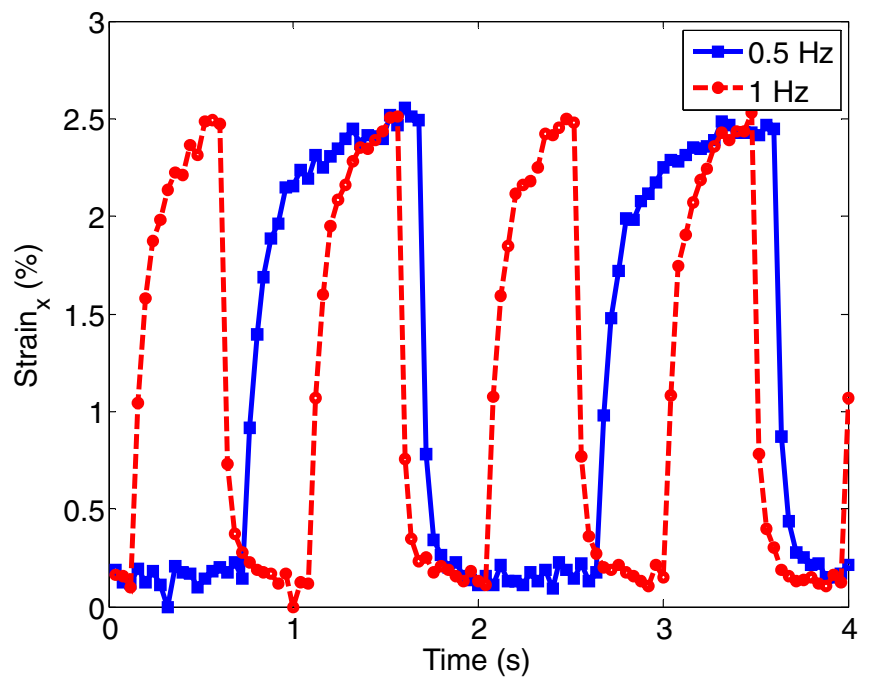

Figure 12. Dynamic response of one $100 \mu \mathrm{m} \times 200 \mu \mathrm{m}$ actuator. The electrical excitation is a $2.6 \mathrm{kV}$ square signal at $1 \mathrm{~Hz}$ for the dashed red line and $0.5 \mathrm{~Hz}$ for the solid blue line. The response time of the actuator is $0.2 \mathrm{~s}$.

variation of the passive intermediate PDMS layer used for bonding.

\subsection{Dynamic response}

The dynamic behavior of one actuator driven with a $2.6 \mathrm{kV}$ square signal at 1 and $0.5 \mathrm{~Hz}$ using a high-voltage amplifier (Model 609E-6 from TREK, Inc.) is shown in figure 12. 25 frames per second are recorded with a Basler A622f camera connected to the microscope, and the images are analyzed with our image-processing program to characterize the actuation strain over time. One of the images at the zero voltage is used as the reference off-state image to measure the dots' displacement of other images. The response time is $0.2 \mathrm{~s}$, which is sufficient to actuate the cells with relevant biological frequencies

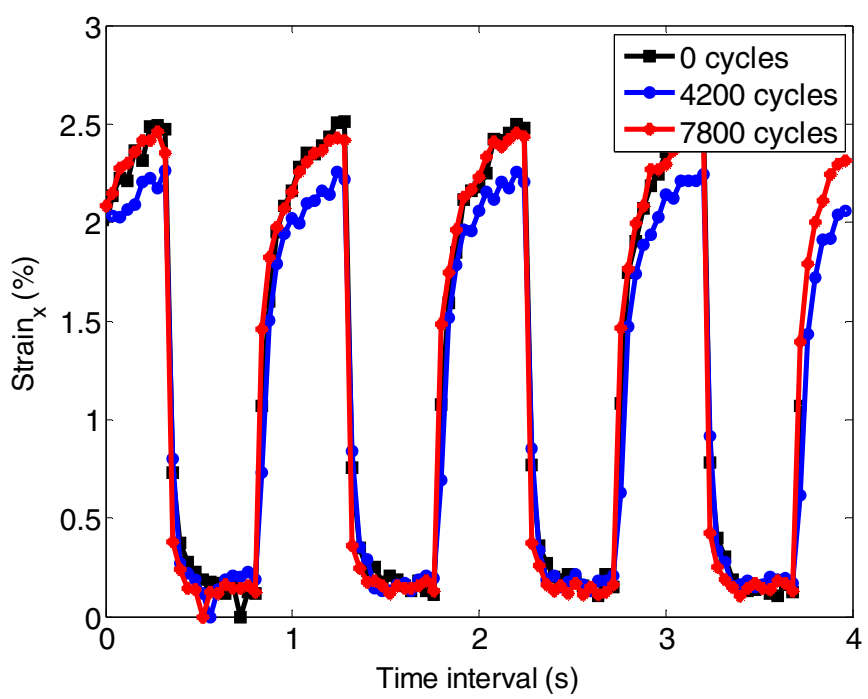

Figure 13. Lifetime measurement: actuation strain of a $100 \mu \mathrm{m} \times$ $200 \mu \mathrm{m}$ actuator with an excitation voltage of $2.6 \mathrm{kV}$ square signal at $1 \mathrm{~Hz}$ frequency is measured initially, after 4200 cycles and after 7800 cycles. The strain level is reproducible within $0.2 \%$ accuracy.

(0.05-5 Hz) [19]. The response time is limited here by the electrical RC time constant of high resistive electrodes. There is a tradeoff between the response time and the achievable strain of the actuators due to the inverse link between the resistance and Young's modulus of ion-implanted electrodes.

\subsection{Lifetime measurement}

Cells regulate their biochemical responses over a timescale of a few minutes to a few hours for periodic strains [16, 19]. We actuated our devices with a $2.6 \mathrm{kV}$ square signal at $1 \mathrm{~Hz}$ for $130 \mathrm{~min}$. Every $10 \mathrm{~min}, 100$ frames, corresponding to $4 \mathrm{~s}$ of operation, are recorded and analyzed. Figure 13 shows the actuation strain of an actuator at the beginning of the test, after $70 \mathrm{~min}$ and after $130 \mathrm{~min}$. The response time has not changed and the strain level is reproducible with an accuracy of $0.2 \%$ over the test period. Lifetimes of more than 1.3 million cycles have been reported for buckling mode DEA actuators made from non-pre-streched silicone membranes with ionimplanted electrodes operated at $1.5 \mathrm{kV}$ [37]. In our group, tunable lenses with ionic liquid electrodes have also been successfully operated for thousands of cycles. However, to operate the device in salt water (similar to the cell culture medium), it will be necessary to seal the PDMS membrane, as it is slightly porous and absorbs water, leading to a breakdown after half an hour periodic actuation (at $1 \mathrm{~Hz}$ ). Our planned approach is to deposit a $100 \mathrm{~nm}$ thick parylene layer on the PDMS membrane and later etch this layer away with plasma $\mathrm{O}_{2}$. It has been reported that this procedure caulks the PDMS pores and thus seals the membrane without stiffening it [45].

\section{Conclusion}

We have presented the microfabrication and characterization of an array of dielectric elastomer microactuators that can serve as a tool to study the mechanotransduction of individual 
cells. The chip consists of an array of $72100 \mu \mathrm{m} \times 200 \mu \mathrm{m}$ EAP actuators in three separate groups, making it possible to actuate three different groups of single cells with different strain levels and frequencies in a single experiment. This array of microactuators used as a high throughput single cell stretcher device can play an important role in understanding how cells decipher and respond to a mechanical stimulation.

The chip represents a new geometry for EAP devices, with chip-scale actuators only free to move over microfabricated trenches, thus delivering uniaxial strain over $50 \mu \mathrm{m} \times$ $50 \mu \mathrm{m}$ areas. We have shown that the low-energy metal ion implantation is an effective and reliable technique to fabricate $100 \mu \mathrm{m}$ wide compliant electrodes for DEAs. This addresses the lack of suitable microfabrication techniques to pattern $\mu \mathrm{m}$ scale compliant electrodes on silicone membranes, which was a major limiting factor in the miniaturizing dielectric elastomer actuators.

The displacement and strain profiles of the actuators were measured by tracking the position of an array of $4 \mu \mathrm{m}$ diameter dots deposited on the actuators. At the center of the actuator, the in-plane uniaxial strain is maximum and the strain variation is negligible $(0.2 \%$ variation) over an area of $50 \mu \mathrm{m}^{2}$, comparable to the size of a single cell. The in-plane uniaxial actuation strain reaches $4.7 \%$ at $2.9 \mathrm{kV}$. Comparing the experimental and simulated results validates our FEM simulation as a suitable optimization tool. The response time of the actuator is $0.2 \mathrm{~s}$ amply sufficient to stimulate cells at relevant biological frequencies.

\section{Acknowledgments}

We gratefully acknowledge financial support from the Swiss National Science Foundation grant 200020-130453, thank Dr A Franco-Obregon from the ETHZ-LBB for helpful advice on cell mechanobiology, Dr A Punning, Dr S Rosset and Dr M Niklaus for their helpful discussion and Dr O Vazquez-Mena from EPFL-LMIS1 for the fabrication of the stencil masks.

\section{References}

[1] Brochu P and Pei Q 2010 Advances in dielectric elastomers for actuators and artificial muscles Macromol. Rapid Commun. 31 10-36

[2] Pelrine R, Kornbluh R, Pei Q and Joseph J 2000 High-speed electrically actuated elastomers with strain greater than 100\% Science $287836-9$

[3] Kovacs G, Lochmatter P and Wissler M 2007 An arm wrestling robot driven by dielectric elastomer actuators Smart Mater. Struct. 16 S306-17

[4] Anderson I A, Tse T C H, Inamura T, O'Brien B, McKay T and Gisby T 2011 Flexidrive: a soft artificial muscle motor Proc. SPIE $797679761 \mathrm{~T}$

[5] Carpi F, Rossi D D, Kornbluh R, Pelrine R and Sommer-Larsen P 2008 Dielectric Elastomers as Electromechanical Transducers (Amsterdam: Elsevier)

[6] Kornbluh R D, Pelrine R, Prahlad H, Wong-Foy A, McCoy B, Kim S, Eckerle J and Low T 2011 From boots to buoys: promises and challenges of dielectric elastomer energy harvesting Proc. SPIE 79767976051

[7] Jordi C, Michel S, Dürager C, Bormann A, Gebhardt C and Kovacs G 2010 Large planar dielectric elastomer actuators for fish-like propulsion of an airship Proc. SPIE $\mathbf{7 6 4 2} 764223$

[8] Niu X, Brochu P, Salazar B and Pei Q 2011 Refreshable tactile displays based on bistable electroactive polymer Proc. SPIE 7976797610

[9] Lotz P, Matysek M and Schlaak H F 2011 Fabrication and application of miniaturized dielectric elastomer stack actuators IEEE/ASME Trans. Mechatronics 16 56-66

[10] Pimpin A, Suzuki Y and Kasagi N 2004 Micro electrostrictive actuator with metal compliant electrodes for flow control applications Proc. 17th IEEE Int. Conf. Micro Electro Mechanical Systems (Maastricht) pp 478-81

[11] Aschwanden M and Stemmer 2007 A low voltage, highly tunable diffraction grating based on dielectric elastomer actuators Proc. SPIE $\mathbf{6 5 2 4} 65241 \mathrm{~N}$

[12] Rosset S, Niklaus M, Dubois P and Shea H R 2009 Large-stroke dielectric elastomer actuators with ion-implanted electrodes J. Microelectromech. Syst. 18 1300-8

[13] Punning A, Akbari S, Niklaus M and Shea H R 2011 Multilayer dielectric elastomer actuators with ion implanted electrodes Proc. SPIE $797679760 \mathrm{U}$

[14] Rosset S, Niklaus M, Dubois P and Shea H R 2009 Metal ion implantation for the fabrication of stretchable electrodes on elastomers Adv. Funct. Mater. 19 470-8

[15] Niklaus M and Shea H R 2011 Electrical conductivity and Young's modulus of flexible nanocomposites made by metal ion implantation of polydimethylsiloxane: the relationship between nanostructure and macroscopic properties Acta Mater. 59 830-40

[16] Song G, Jub Y, Shena X, Luoa Q, Shia Y and Qina J 2007 Mechanical stretch promotes proliferation of rat bone marrow mesenchymal stem cells Colloids and Surfaces B: Biointerfaces 58 271-7

[17] Putnam A J, Cunningham J J, Dennis R G, Linderman J J and Mooney D J 1998 Microtubule assembly is regulated by externally applied strain in cultured smooth muscle cells J. Cell Sci. 111 3379-87

[18] Sarasa-Renedo A and Chiquet M 2005 Mechanical signals regulating extracellular matrix gene expression in fibroblasts Scand. J. Med. Sci. Sports 15 223-30

[19] Wang J H C and Thampatty B C 2006 An introductory review of cell mechanobiology Biomech. Model Mechanobiol. $51-16$

[20] Brown T D 2000 Techniques for mechanical stimulation of cells in vitro: a review J. Biomech. 33 3-14

[21] Serrell D B, Oreskovic T L, Slifka A J, Mahajan R L and Finch D S 2007 A uniaxial bioMEMS device for quantitative force-displacement measurements Biomed. Microdevices 9 267-75

[22] Scuor N, Gallina P, Panchawagh H V, Mahajan R L, Sbaizero O and Sergo V 2006 Design of a novel MEMS platform for the biaxial stimulation of living cells Biomed. Microdevices 8 239-46

[23] Bélanger M-C and Marois Y 2001 Hemocompatibility, biocompatibility, inflammatory and in vivo studies of primary reference materials low-density polyethylene and polydimethylsiloxane: a review J. Biomed. Mater. Res. 58 467-77

[24] Kofod G, Kornbluh R, Pelrine R and Sommer-Larsen P Actuation response of polyacrylate dielectric elastomers Proc. SPIE 4329 141-7

[25] Kam L and Boxer S T 2001 Cell adhesion to protein-micropatterned-supported lipid bilayer membranes J. Biomed. Mater. Res. 55 487-95

[26] Csucs G, Michel R, Lussi J W, Textor M and Danuser G 2003 Microcontact printing of novel co-polymers in combination with proteins for cell-biological applications Biomaterials 24 1713-20 
[27] Onuma E K and Hui S-W 1998 Electric field-directed cell shape changes, displacement, and cytoskeletal reorganization are calcium dependent J. Cell Biol. 106 2067-75

[28] Kuznetsova T G, Starodubtseva M N, Yegorenkov N I, Chizhik S A and Zhdanov R I 2007 Atomic force microscopy probing of cell elasticity Micron 38 824-33

[29] Molberg M, Leterrier Y, Plummer C J G, Walder C, Löwe C, Opris D M, Nüesch F A, Bauer A and Månson J A E 2009 Frequency dependent dielectric and mechanical behavior of elastomers for actuator applications J. Appl. Phys. 106054112

[30] Akbari S, Nicklaus M and Shea H R 2010 Arrays of EAP micro-actuators for single-cell stretching applications Proc. SPIE $764276420 \mathrm{H}$

[31] Kornbluh R, Pelrine R, Pei Q, Oh S and Joseph J 2000 Ultrahigh strain response of field-actuated elastomeric polymers Proc. SPIE 3987 51-64

[32] Koh S J A, Li T, Zhou J, Zhao X, Hong W, Zhu J and Suo Z 2011 Mechanisms of large actuation strain in dielectric elastomers J. Polym. Sci. B 49 504-15

[33] Quaglio M, Canavese G, Giuri E, Marasso S L, Perrone D, Cocuzza M and Pirri C F 2008 Evaluation of different PDMS interconnection solutions for silicon, Pyrex and COC microfluidic Chips J. Micromech. Microeng. 18055012

[34] www.ANSYS.com

[35] http://www1.dowcorning.com/DataFiles/ 090007c88020bcca.pdf

[36] http://www.icoflex.com

[37] Niklaus M, Rosset S, Dubois P and Shea H R 2009 Ion-implanted compliant electrodes used in dielectric electroactive polymer actuators with large displacement Procedia Chemistry 1 702-5
[38] Dubois P, Rosset S, Niklaus M, Dadras M and Shea H R 2008 Voltage control of the resonance frequency of dielectric electroactive polymer (DEAP) membranes J. Micromech. Syst. 17 1072-81

[39] Wu H, Huang B and Zare R N 2005 Construction of microfluidic chips using polydimethylsiloxane for adhesive bonding Lab Chip 5 1393-8

[40] Satyanarayana S, Karnik R N and Majumdar A 2005 Stamp-and-stick room-temperature bonding technique for microdevices J. Micromech. Syst. 14 392-9

[41] Mark A, Eddings M A, Johnson M A and Gale B K 2008 Determining the optimal PDMS-PDMS bonding technique for microfluidic devices J. Micromech. Microeng. 18067001

[42] Khanafer K, Duprey A, Schlicht M and Berguer R 2009 Effects of strain rate, mixing ratio, and stress-strain definition on the mechanical behavior of the polydimethylsiloxane (PDMS) material as related to its biological applications Biomed. Microdevices 11 503-8

[43] Brugger J, Berenschot J W, Kuiper S, Nijdam W, Otter B and Elwenspoek M 2000 Resistless patterning of sub-micron structures by evaporation through nanostencils Microelectron. Eng. 53 403-5

[44] Vazquez-Mena O, Sidler K, Savu V, Park C W, Villanueva L G and Brugger J 2011 Reliable and improved nanoscale stencil lithography by membrane stabilization, blurring and clogging corrections IEEE Trans. Nanotechnol. $10352-7$

[45] Sawano S, Naka K, Werber A, Zappe H and Konishi S 2008 Sealing method of PDMS as elastic material for mems Proc. IEEE 21st MEMS 2008 Int. Conf. (Tucson, USA) pp 419-22 